\title{
Social Media Adoption in Yemeni Local NGOs
}

\author{
Mohammed Honinah ${ }^{1}$, Wail Alhakimi ${ }^{2}$ \\ ${ }^{1}$ School of Business, Lebanese International University, Yemen \\ ${ }^{2}$ Associate Professor of Marketing, Taiz University, Yemen \\ Correspondence: Wail Alhakimi, Taiz University, Yemen. E-mail: wail.alhakimi@taiz.edu.ye \\ Received: April 14, 2021 \\ Accepted: July 16, 2021 \\ Online Published: September 10, 2021 \\ doi:10.48110/joi.v2i2.36 \\ URL: https://doi.org/10.48110/joi.v2i2.36
}

\begin{abstract}
Social media use is rapidly increasing as its platforms keep offering excellent opportunities for individuals and organizations, including NGOs, to develop better outreach with communities, donors and stakeholders, save costs and improve service. This study explores quantitative evidence derived from a survey involving 96 participants from 11 local NGOs in Yemen. The survey responses are analyzed using descriptive statistics that includes means and standard deviations to examine the initially identified 6 Technology-Organization-Environment factors (Technological Factors: perceived benefit, compatibility, complexity; Organizational Factor: top management support; Environmental Factors: bandwagon pressure and competitive pressure). The results suggest that the factors (perceived benefit, compatibility, complexity, top management support, and competitive pressure) are important for social media adoption. It was found that bandwagon pressure is the only factor that does not have a significant role in social media adoption. This study provides a foundation for future social media adoption research as well as useful guidance to NGOs that desire to use social media effectively to benefit their organizations. The findings can be useful to managers and communication officers of NGOs. In this study, it is recommended that understanding the factors related to adoption of social media by Local NGOs will help decision-makers be in a better position to enhance future social media adoption and adoption strategies and accomplish the best outcomes of social media utilizations.
\end{abstract}

Keywords: Social Media Adoption, Technological Factors, Organizational Factor, Environmental Factors, NGOs, Yemen

\section{Introduction}

Social media represents a new responsive approach for conducting any business (Andzulis, Panagopoulos \& Rapp, 2012). It has the ability to change how businesses operate to ultimately achieve business transformation (Aral, Dellarocas \& Godes, 2013). Social media is adopted progressively in all organizations around the world. This adoption of social media is likely to continue and control how businesses operate (Andriole, 2010). Consequently, all kinds of businesses, irrespective to their business and size, have recognized the significance of social media adoption (Nah \& Saxton, 2013). According to Merrill, Latham, Santalesa and Navetta (2011), the adoption of social media tremendously upsurges the profits of any organization in areas like promotion, advertisement, customer service, product development, branding word of mouth advocacy as well (Parveen, Jaafar, \& Ainin, 2015). According to Verheyden and Goeman (2013), in the new world, these advantages are no longer monopolized merely for organizations of a big size

Obviously, the positive influence of social media has lately grabbed the attention of many private and public organizations that include non-governmental organizations. These organizations use these applications as tools to improve general services for either customers of business-oriented companies or beneficiaries of public and nonprofit organizations (Mergel \& Bretschneider, 2013; Ellison \& Hardey, 2013). stated, "Social media is more than just a communication channel .... it can go beyond improving communication between public sector organizations and their audience" (Thackery, Neiger, Smith \& Van Wagenen, 2012, p.242). Therefore, adoption of social media can generate opportunities to develop community-based corporations via improving engagement with the public and receiving feedbacks (Safko \& Brake, 2009). According Waters \& Williams (2011), this will help to create healthy relationship and interaction with the community members. 
Researches on NGOs social media adoption are very limited. One of the studies that tackled social media adoption within NGOs suggested that NGOs must learn how to better utilize social media applications as tools that can promote interactions among all parties involved in any project. Then, they will be capable of improving communication within the community, donors and different stakeholders (Abubakar, Patricia, Samuel, \& Totolo, 2017).

According to Hattez (2015), the argument about the necessity of using applications such as Twitter and Facebook for nonprofit organizations does not eradicate the fact that these applications provide golden opportunities for online interaction that can ultimately lead to empowering the local community. For instance, using social media tools can provide great help on gathering different information as well as eliminating communication boundaries which will lead to improving information exchange among different (Yates, Wagner, \& Majchrzak, 2010).

NGOs around the world are endeavoring to provide professional services that are more effective and efficient, so that they can meet the constant increase of demands and expectations from donors and different stakeholders, and simultaneously overcome the obstacles of reducing public budgets (Osimo, 2008). In addition, social media provides chances for cost reductions and flexibility (Lim \& Palacios-Marques, 2010). According to Chang and Kannan (2008), it gives better service delivery and effective feedback from citizens. Another study by Osimo (2008) discussed social media adoption within public and non-profit organizations and found that social media is useful as a tool for various types of organizations to accomplish their objectives. Therefore, social media applications have been utilized regularly within organization activities and cross agency cooperation for different purposes, which include law enforcement and knowledge management (Osimo, 2008).

According to Osimo (2008), the use of social media applications requires organizations to adapt different organizational culture. It is important to make sure that the new opportunities provided by social media applications will be cautiously used and managed to maximize open interactions, minimize the risk of losing confidentiality and making sure that all communication either formal or informal meet the required standards (Meijer \& Thaens, 2010).

NGOs have adopted the private sector moves by adopting and investing in social media applications as an essential element of information technology policy to provide effective public services (Dadashzadeh, 2010). Using social media applications at NGOs is a significant resource for enhancing service delivery, including community services and operations (Coco, 2014). While the current information on social media adoption is comprehensive, it mainly concentrates on the field of profit organizations (Sivarajah et al., 2014). Nevertheless, for the strategic differences between profit originations and nonprofit organizations such as differences on operating goals, administration, and motivations, the existing understanding about social media adoption may not be applicable to nonprofit organizations (Coco, 2014). Some studies discussed social media and NGOs. However, the so mentioned studies did not clarify the factors that lead to social media adoption, but rather they focus on other social media aspects like crises management, social media evaluation and fundraising.

The majority of social media studies in the context of NGOs have focused on crises management in social media. For instance, Vistbacka (2017) studied the theories that are considered important to the field of crisis management and crisis communication within NGOs. Moreover, Ward (2011) studied crisis management and explores whether NGOs are suing social media in times of crisis. Another study by Hattez (2015) discussed mass media effects on NGOs. Coco (2014) focused on social media evaluation for NGOs and the ways to increase the performance of Oxfam Italia on Facebook. Apart from social media and crisis management, another study focused on NGOs and social media fundraising. This study explores social media success on advocating for charity among many nonprofit organizations in a community (Whitaker, 2014). According to Baxter, Connolly and Stansfield (2010), to have a successful implementation to social media adoption, it is important to ensure a clear understanding to your objectives of using these applications.

The expansion of framework to build better understanding on social media adoption factors in NGOs is limited (Sivarajah et al., 2014). Studies on this topic are limited because existing studies are mostly focusing more on social media adoption within profit organizations. Notable exceptions of studies that focused on social media adoption with NGOs include the work of Abubakar et al. (2017), who explored the factors of social media adoption by Women Non-governmental Organizations (WNGOs). This study aimed at examining the factors of social media adoption by WNGOs in North-West of Nigeria, using Technology-Organization-Environment (TOE) Framework. This study, however, was built on a single case study in the North-West of Nigeria, which merely emphasizes on women. Therefore, it did not reveal the wider community due to the different size and structure of local governments from one country to another. Hence, understanding factors driving social media adoption within a specific context can help managers of NGOs identify the right approaches of utilizing social media and realize expected advantages. 
Ellison and Hardey (2013) mentioned that although many studies have highlighted social media application design, social media use within organization is still ambiguous. In the other hand, Bonsón, Torres, Royo and Flores (2012) pointed Ellison has found out significant impacts of social media use such as cost reduction, performance improvement, but there are many other factors that need to be uncovered. Many researches confirm that social media generates better engagement with the community, reduces costs, and improves organizational image. However, further research is needed to better comprehend social media adoption within organizations (Bonsón et al., 2012).

This study aims at improving the comprehension of social media adoption within local NGOs in Yemen. It concentrates on the factors affecting social media adoption. This study contributes to the body of knowledge by adding the technology of adoption to the NGOs literature and confirming the adoption of Technological, Organizational and Environmental (TOE) model in the context of social media adoption within local NGOs in Yemen. The finding of this study might give the decision makers at NGOs an understanding of the factors that can lead to adopting social media applications. This will consequently assist NGOs in Yemen to develop specific communication strategies and policies that can help them better utilize and adopt social media applications.

The significance of this study lies in its contribution to the literature of social media adoption within NGOs. Most of previous studies explored either social media adoption or social media use for communication and collaboration in private and public organizations. However, this study pinpoints the factors that illustrate the adoption of social media in local NGOs. This is done via using technological, organizational, and environmental (TEO) model as a tool to investigate the factors of adopting social media in local NGOs in Yemen. Hence, by linking TOE model with social media adoption within local NGOs, this study can encourage researchers to search for more independent variables that can drive organizational impact in different contexts. Petter, DeLone and McLean (2013) also suggested to ensure reliability the model shall be examined using different domains. Based on the literature review, this study seems to be the first of its kind that explores social media adoption within the context of local NGOs.

Moreover, the comprehension of the factors that affect social media adoption in local NGOs can assist CEOs, project managers, and communication officers to recognize the need for using social media applications in an effective and efficient manner. The findings of this study can also help local NGOs in planning strategies and suggesting guidelines that support a successful social media adoption. Finally, this study hopes that its findings may help officials identify the benefits offered by social media applications such as better engagement with local community, donors, and other stakeholders. The following definitions describe the key terms that are adopted in this study:

- Social Media: a term that was used first in 2005 to describe several forms of Internet-based applications that are based on the concept of having a modern version of the Web (O'Reilly, 2007).

- Adoption: the decision of an individual or organization to make use of an innovation (Rogers, 1995).

- TEO Framework: "The TOE framework is a model that identifies three context groups (technological, organizational, and environmental) that may influence organizational adoption of an innovation" (Rahbi, 2017, p.30).

In attempting to examine factors that impact social media adoption in Yemen, this study aims to answer the following questions:

- What is the current level of social media adoption by local NGOs in Yemen?

- What are the key factors that influence the adoption of social media in Yemeni local Non-Profit Organizations (NGOs)?

- What are the significant differences of social media adoption among Yemeni local NGOs?

\section{Literature Review}

\subsection{Social Media}

O'Reilly (2007) stated that social media is a term that started in 2005 to describe several types of Internet applications that are based on the concept of having a contemporary form of the Web. It is usually referred to as Web 2.0, a system in which every Web user can contribute to changing the Web content (O'Reilly, 2007). Social media is a new class of information technologies that facilitates collaboration and interactive social communication via utilizing Internet-based platforms (Kane, Alavi, Labianca, \& Borgatti, 2014). Twitter, Facebook, YouTube, and LinkedIn are considered the most popular of all social media (Kane et al., 2014).

Previous researches have provided different classifications for social media applications. For Instance, Hoegg, Martignoni, Meckel and Stanoevska-Slabeva (2006) classified social media applications into five groups: wikis, blogs, social networks, social booking systems and podcasts. On the other hand, Kaplan and Haenlein (2010) 
characterized social media into six categories that include social networking such as Facebook and blogs, virtual worlds such as "Second Life", joint projects like Wikipedia, sharing multimedia services like "YouTube", and virtual gaming like "World of Warcraft".

According to Parveen (2012), many approaches have been used by different studies to examine the level of adoption for many technological applications within originations. Many previous studies explored technological models to measure technology adoption. For example, Oliveira and Martins (2011) stated that there are five popular models used to measure technological adoption: Diffusion of Innovation (DoI), Technology Acceptance Model (TAM), the Theory of Planned Behaviour (TPB), the Unified Theory of Acceptance and Technology Use (UTATU), and the Technology-Organization-Environment (TOE), which is the model used to measure social media adoption in this study.

Each of the above-mentioned models or theories has different focus and emphasis (Parveen, 2012). For example, DoI model focuses on the role of technological characteristics in adoption, whereas UTAUT and TAM emphasize more on characteristics influencing individual behavior, which makes these two models more practical (Parveen, 2012). Briefly, some models focus on individual- oriented technology adoption such as TPB, TAM, and UTAUT, whereas other models are organizational-oriented models. DoI and TOE are the best examples for organizationaloriented models.

\subsection{Technological Factors}

According to Aghaunor and Fotoh (2006), technological factor refers to technology adoption challenges and advantages. The technological factors include perceived benefit, risk, complexity, and compatibility, which have a significant influence on technology adoption.

\subsubsection{Relative Advantage}

According to Venkatesh and Bala (2013), relative advantage refers to the anticipated benefits which are achieved when an innovation is adopted. In the context of social media adoption within NGOs, relative advantage is defined as the anticipated benefits and advantages accomplished when NGOs adopt social media platforms. According to Howard (2012), researchers and experts suggested that social media provides several advantages to organizations in terms of improving service delivery and public engagement especially during crises and disaster. According to Iacovou et al. (1995) and Abubakar et al. (2017), relative advantage or perceived benefit has a positive significant role in technology adoption research, as it has been used as a main factor in the literature related to the social media relative advantage. Hence, we can conclude that relative advantage is considered in this study for the purpose of providing more literature and evidences on the impact of relative advantage on social media adoption.

\subsubsection{Compatibility}

Many studies highlighted the importance of compatibility in adopting innovation decisions. According to Tan and Teo (1998), compatibility is a significant factor of technological adoption. According to Rogers (1995), compatibility is a terminology that is utilized in the technology innovation literature to describe to what extent a certain innovation is identified compatible with organizational values. Most studies suggested that compatibility plays a role in inspiring organizations to adopt different technological innovations. For instance, Beatty, Shim and Jones (2001) showed that organizations are likely to adopt new technologies when its relative advantage is consistent with the organizational values and standards. Moreover, Thong (1999) also proposed that compatibility is a main factor that influences the decision to adopt internet in business-oriented organizations. In addition, Tan and Teo (1998) proved compatibility has a significant influence on motivating business organizations to adapt the use of Internet.

\subsubsection{Complexity}

According to Thong (1999), complexity is defined by the ease of use of a certain innovation. Although Thong (1999) did not find the relationship between complexity and technology adoption significant, several studies suggested that complexity has a significant impact on the decisions of organizations to use a new technology. These studies emphasized on the need for any new innovation to be flexible and user-friendly. For instance, Rahbi (2017) and Gangwar et al. (2015) suggested that perceived complexity has a significant impact on the decision of organizations to adopt social media platforms.

\subsection{Organizational Factor}

The organizational context is another driver that can affect the decision of organizations to adopt technology. Organizational context refers to the organization features that has an impact on the adoption of an innovation 
(Chau \& Tam, 1997). Many studies indicated that organizational factors influence the adoption of social media. One of the most predominate factor that has been proven to have a significant impact on technological adoption is top management support (Abubakar et al., 2017). Top Management support is the organizational factor considered for this study.

\subsubsection{Top Management}

In the context of social media adoption, top management factor refers to the support provided by top management of an organization, which leads to adopting social media (Abubakar et al., 2017). According to Hameed, Counsell and Swift (2012), top management factor has a significant impact on technology adoption. Without top management, financial and environmental support and providing human resources, adopting any technological innovation is likely to be an impossible task (Teo et al., 2009). Many previous researches confirmed the significant influence of top management on technological adoption (Rahbi, 2017; Moon \& Norris, 2005)

Damanpour and Schneider (2009) explored top management support in organizational context and confirmed that the lack of employees' motivation and organizational rigid bureaucracy are obvious elements that hinder technology adoption. Top management factor significantly affects employee's motivation, which can also generate a healthy atmosphere for individuals working in any organization, who do not resist change and adopt new technology (Osimo, 2008). In addition, staff training provided by top management can also play an important role in building staff confidence to adopt technological innovation in their workplace (Jeyaraj et al., 2006).

\subsection{Environmental Factors}

The environmental factors represent the third driver in the TOE framework, which have been found to influence social media adoption in organizations. The literature indicated that looking into the organizational environment could assist in raising an understanding of information technology uptake for these organizations (Kapurubandara \& Lawson, 2006). Some researches viewed sentimental factors as inconsiderable comparing to other factors of innovation adoption (Premkumar, 2003). However, studies that explored environmental factors found them to be influential in the adoption of social media SMEs in IT organizations (Ramdani, Kawalek, \& Lorenzo, 2009; Jeon, Han \& Lee, 2006; Grandon \& Pearson, 2004; Kuan \& Chau, 2001; Mehrtens, Cragg \& Mills, 2001; Rahbi, 2017; Battaglia, 2016). Several environmental factors have been recognized to have a great impact on the choice of organizations to adopt a new technological innovation. These factors include customer pressure, bandwagon pressure, competitive pressure, market opportunity, organization support, and IT infrastructure. Bandwagon pressure and competitive pressure are the two environmental factors chosen for this study.

\subsubsection{Bandwagon Pressure}

Bandwagon pressure is a terminology that was first used by Rosenkopf and Abrahamson (1999). It was used to define the situation in which an organization makes a decision to adopt an innovation merely because many other institutions of the same or different businesses are using the same innovation. According to Sinclaire and Vogus (2011), this phenomenon creates anxiety within the organization that has not adopted that technological innovation yet. According to them, it makes them feel behind, which will lead to losing customers, who are always looking for new innovations. Many studies have explored bandwagon pressure and found it to have a significant influence on the decision of organizations to adopt an innovation. An example of these studies is Flanagin (2006), who illustrated the importance of bandwagon pressure as a main factor that influences technological adoption. Sometimes referred to "herd behavior", bandwagon pressure has proven to play an important role in the decision made by organizations to adopt social media application. Bandwagon makes organizations more secured in adopting technology innovation, improves performance, and reduces the risk of being the only one investing on such a technology.

\subsubsection{Competitive Pressure}

Within the context of social media adoption, competitive pressure refers to the motive that organizations of the same industry have for social media adoption (Battaglia, 2016). Most of the studies that have explored competitive pressure as a factor for technology adoption have found this factor to have an essential role in adoption decision (Cao et al., 2018). Haller \& Siedschlag (2011) confirmed that organizations would be strongly motivated to adopt social networking platforms if they realize that their close competitors are utilizing social networking applications as a tool to attract and interact with more customers. The concern of every organization around the world in today's market is to gain a competitive advantage and adopt new networking platforms (Haller \& Siedschlag, 2011). 


\section{Methods}

The population of the study is all local NGOs in Yemen, which are registered within the United Nations System, have valid email addresses, and are located in Sana'a but have different branches across the country. According to OCHA (2019), 42 local NGOs are registered within its system for 2019. Only 11 local NGOs were targeted. The survey was mainly completed by the officers in charge of communication or public relations, project officers, senior managers, and chief executive officers. Hence, respondents are people who usually work either technically or strategically in social media adoption, which leads to good data quality. This study covers different variables (factors related to TEO framework). Adoption of social media is measured via six items adapted from Cesaroni and Consoli (2015) and AlSharji et al. (2018). These items identify NGOs level of utilization of social media, social media platforms used, number of years since initial adoption, use as an advocacy tool, staff hours spent on social media per day, and budget allocated. Technology factors of social media adoption are measured using seventeen items for three technological variables (relative advantage, compatibility, and complexity) adopted from Grandon and Pearson (2004), Al-Qirim (2007), Abubakar et al. (2017) and AlSharji et al. (2018). Top management drive items are adapted from Abubakar et al. (2017) and AlSharji et al. (2018). Moreover, five items for two environmental factors (bandwagon pressure and competitive pressure) were derived from Sun and Douglas (2013), Rahbi (2017), Abubakar et al. (2017) and AlSharji et al. (2018).

To ensure that the scale items are verified in this study, the adopted survey was sent to professionals working within the United Nation Development Programme (UNDP). Moreover, reliability of the items is tested using Cronbach's alpha tool for indicating the type of reliability reported. Cronbach's alpha coefficients for all the constructs in the model exceed 0.7 with the coefficients scores ranging between 0.817 and 0.959 , indicating high internal consistency and reliable constructs. The questionnaire outputs were encoded and analyzed using the Statistical Package for Social Sciences (SPSS). One-way analysis of variance (ANOVA) was used to determine whether there are any statistically significant differences among the eleven local NGOs. Finally, factors are analyzed using descriptive statistics that include maximum, minimum, means, standard deviations, and sig value data to examine their significant role in social media adoption.

\section{Findings}

Table 1 presents the names of the local NGOs and the total number of participants for each NGO. As presented in this table, the total number of respondents participating in this survey from 11 local NGOs is 96.

Table 1. Name of organizations participating on the survey and total number of participants

\begin{tabular}{rlcc}
\hline \multicolumn{1}{c}{ Organization } & Frequency & Percent \\
\hline 1. & National Foundation for Development and Humanitarian Response & 10 & 10.4 \\
& (NFDHR) & 9 & 9.4 \\
2. Relief and Development Peer Foundation (RDP) & 8 & 8.3 \\
3. & Ghadaq For Development & 4 & 4.2 \\
4. Sustainable Development Foundation (SDF) & 6 & 6.3 \\
5. Millennium Development Foundation (MDF) & 10 & 10.4 \\
6. Youth Leadership Development Foundation (YLDF) & 30 & 31.3 \\
7. Yemen Alkhair for Relief \& Development Foundation & 4 & 4.2 \\
8. For all Foundation (FAF) & 2 & 2.1 \\
9. Mayar Foundation for Development (MFD) & 5 & 5.2 \\
10. Resilient Communities Organization (RECO) & 8 & 8.3 \\
11. Building Foundation for Development (BFD) & $\mathbf{9 6}$ & \\
\hline
\end{tabular}

Regarding the position of the respondents, the position of project officers gets the highest percentage (38.5\%). The second rank is represented by the position of communication officer (25\%). The results indicate the big number of project officers in NGOs compared to communication officers and senior managers, who present (16\%) out of the total percentage of respondents. Expectedly, the lowest percentage of top managements that include CEOs is attributed to their limited number. This also shows the interest of project and communication officers in being part of this study, as they are the ones who are always keen to promote success stories of their projects in different social media platforms. 
The results show that Facebook, WhatsApp, twitter and YouTube are the four most popular social media platforms adopted by local NGOs in Yemen. A substantial percentage of $91 \%$ of NGOs indicate that they have a presence on Facebook. WhatsApp is the second most widely adopted platform with $85.4 \%$. In addition, nearly two-quarters of are found to use Twitter and YouTube. Instagram, blogs and Flickr are the least popular platforms used by local NGOs in Yemen. These results are consistent with Yemen social media statistics, as 93 percent of the population in Yemen, who access Internet, use Facebook, whereas 92 percent use WhatsApp. According to the same report, YouTube is also popular with $41 \%$ (Battaglia, 2016).

As for the level of social media utilizations rate. Moderate use of social media took the highest proportion (44.8\%) followed by extensive use of social media (31\%). The lowest percentage $(5.2 \%)$ is represented by minimal use of social media. These results indicate that the individuals working within local NGOs in Yemen are aware of the importance of social media utilization in seeking different strategic advantages. In addition, the results show that the majority of local NGOs in Yemen are old adopters who have been using social media for more than 4 years (44.8\%). The second highest percentage represents those who have been using social media for 3-4 years, whereas the lowest percentage $(18.8 \%)$ represents new social media adopters. This may indicate that most of the local NGOs in Yemen are social media adopters, and they have a good experience in how to effectively utilize social media to advocate more fun and showcase the success stories of their interventions using their social media platforms. Using social media, NGOs in Yemen are more proactive about bearing witness to the events by releasing stories of what they have observed.

The findings revealed the majority of respondents $(50 \%)$ said they are "quite a lot" using social media for advocacy purposes. This suggests that they tend to use social media to communicate with donors and stakeholders rather than as an administrative tool. The second highest proportion (24\%) represents the extensive use of social media as an advocacy tool. The rest of percentage $(25 \%)$ represents those who answered with little and very little. These results show that the majority of participants are aware of the importance of utilizing social media as an advocacy tool. Therefore, people around the world can know more about the humanitarian crises in Yemen. The results also indicate that $61.5 \%$ of respondents spent less than 5 hours a day logged into their social media accounts. The remaining 32.3\% spent between 6 to 10 hours per day. The results might reveal a lack of social media strategy to allow employees to access social media. Another explanation could be owners-managers' misconceptions about the negative impact of using social media on work productivity.

As for the budget allocated to social media out of the budget allocated for communications in the NGO, the highest proportion $(63.5 \%$ ) represents the budget $0-20 \%$. This can indicate that NGOs in Yemen do not only use social media because of its effectiveness in advocating and outreaching different audience, but also because of its efficient costs compared to the traditional media that is very expensive and less effective. The lowest percentage (2.1\%) represents the budget (more than $40 \%$ ). Based on previous results of social adoption, it can be concluded that most of the participants of this survey believe in the significance of adopting social media, but not allocating a lot of budget for it, as social media platforms are created to outperform traditional media that is usually costly and not effective. In addition, being aware of the greater need to inform, educate, and advertise the need for social media in more peripheral countries can help humanitarian organizations better allocate resources when determining public relations budgets.

One-way analysis of variance (ANOVA) was carried out to determine whether there are any statistically significant differences among the eleven local NGOs. The results indicates that there is no significant difference among individuals from the eleven local NGOs. This can indicate that local NGOs in Yemen use similar social media strategies. It also indicates that there is a unanimous agreement on the importance of adopting social media among local NGOs in Yemen.

\subsection{Relative Advantage}

As shown in Table 2, item 1 (social media allows us to learn more about other NGOs and donors) has the highest average (3.65) and a sig value equal to $.006(\mu=3.6>3 ; p=.006<.05)$. Therefore, item 1 is found to have a significant difference from the neutral value of 3 , as the sig value is less than 0.05 . This also indicates that the respondents agree with this statement, as the average value is greater than 3. Item 6 (social media provides new opportunities to our NGO) has the lowest average (3.37) and a sig value of .000 ( $\mu=3.37>3 ; p=.000<.05)$. Likewise, the results of item 6 indicate that the item has significant difference from the neutral value 3 , as its sig value is less than 0.05 . This indicates that the respondents agree with statement 6 , as the average value is greater than 3. The average of the six items of relative advantage is equal to $3.52(\mu=3.52>3)$, which is greater than 3 . Briefly, the results of the average and sig value indicate that the top relative advantage factor has a significant role in social media adoption. A small number of studies has supported the impact of relative advantage on social media adoption, especially in the context of organizational technology. One of those studies is conducted by 
Parveen (2012), who explored social media adoption in business companies using business organizations in five different industries. He suggested that relative advantage is an essential factor that affects social media adoption within organizations.

Table 2. Relative Advantage

\begin{tabular}{|c|c|c|c|c|c|}
\hline Relative advantage & Mean & Std. Deviation & $\mathbf{t}$ & df & $\begin{array}{l}\text { Sig. }(2- \\
\text { tailed })\end{array}$ \\
\hline $\begin{array}{l}\text { 1. "Social media allows us to learn more } \\
\text { about other NGOs and donors?" }\end{array}$ & 3.6563 & 1.36750 & 2.827 & 95 & .006 \\
\hline $\begin{array}{l}\text { 2. "Social media allows for better } \\
\text { promoting and advocacy?" }\end{array}$ & 3.6042 & 1.25219 & 3.633 & 95 & .000 \\
\hline $\begin{array}{l}\text { 3. "Social media enhances our NGO's } \\
\text { image?" }\end{array}$ & 3.5938 & 1.30245 & 3.172 & 95 & .002 \\
\hline $\begin{array}{l}\text { 4. "Social media allows us to accomplish } \\
\text { specific tasks more quickly?" }\end{array}$ & 3.5104 & 1.37645 & 4.702 & 95 & .000 \\
\hline $\begin{array}{l}\text { 5. "Social media allows us to enhance our } \\
\text { productivity?" }\end{array}$ & 3.4167 & 1.28691 & 4.727 & 95 & .000 \\
\hline $\begin{array}{l}\text { 6. "Social media provides new } \\
\text { opportunities to our NGO?" }\end{array}$ & 3.3750 & 1.29980 & 4.467 & 95 & .000 \\
\hline Average & 3.5260 & & & & \\
\hline
\end{tabular}

\subsection{Compatibility}

As shown in Table 3, item 1 (social media is compatible with our culture and values) has the highest average of compatibility (3.45) and a sig value equal to $.000(\mu=3.45>3 ; p=.000>.05)$. Therefore, item 1 is found to have a significant difference from the neutral value of 3 , as the sig value is less than 0.05 . Therefore, the average value that is greater than 3 indicates that the respondents agree with this statement. Item 4 (social media legal issues are compatible with us) has lowest average (3.11) and a sig value of .346 ( $\mu=3.1>/=3 ; \mathrm{p}=.346>.05)$. Therefore, item 4 is found to have insignificant difference from the neutral mean value of 3 . Since the sig value (greater than five) is insignificant and the average value is close to 3 , the results indicate that the respondents neither agree nor disagree with item 4 statement. However, the average of the four items of compatibility factor is equal to 3.29 ( $\mu=$ $3.29>3$ ), which is great than 3 . Therefore, the results indicate that the compatibility factor has a significant role in social media adoption.

Although several studies pinpointed compatibility as a significant factor in adopting technological innovation, the studies by Tan and Teo (1998), Flanagin, (2006), Henderson et al. (2012), and Beatty et al. (2001) are based on specific context and their data cannot be taken for granted to be compatible with social media adoption in Yemeni Local NGOs. However, many studies showed that compatibility has a significant role in influencing social media adoption in organizations. For example, Parveen (2012) underlined the fact that compatibility is an essential factor that has a significant influence on social media adoption based on organization values and standards. In addition, the most recent study conducted by Abubakar et al. (2017) suggested that compatibility is a significant factor influencing the decision to adopt social media on SMEs.

Table 3. Compatibility

\begin{tabular}{lccccc}
\hline \multicolumn{1}{c}{ Compatibility } & Mean & Std. Deviation & t & df & $\begin{array}{c}\text { Sig. (2- } \\
\text { tailed) }\end{array}$ \\
\hline 1. "Social media is compatible with our culture & 3.4583 & 1.11371 & 4.032 & 95 & .000 \\
& & & & & \\
and values?" & 3.4583 & 1.16001 & 3.871 & 95 & .000 \\
2. "Social media is compatible with our preferred & & & & & \\
$\quad \begin{array}{l}\text { work practices?" } \\
\text { 3. "Social media security is compatible with us?" }\end{array}$ & 3.1458 & 1.17857 & 1.212 & 95 & .228 \\
$\begin{array}{l}\text { 4. "Social media legal issues are compatible with } \\
\quad \begin{array}{l}\text { us?" } \\
\text { Average }\end{array}\end{array}$ & 3.1146 & 1.18650 & .946 & 95 & .346 \\
\hline
\end{tabular}




\subsection{Complexity}

As shown in Table 4, item 1 (Interaction with social media is clear and understandable) has the highest average (3.64) and a sig value equal to $.038(\mu=3.6>3 ; p=.038<.05)$. Therefore, item 1 is found to have significant difference from the neutral value of 3 , since sig value is less than 0.05 . Since the mean value is greater than 3 , the respondents agree with item 1. Item 5 (I find it easy to get social media to do what I want to do) has the lowest average (3.28) and a sig value of $.000(\mu=3.28>3 ; p=.000<.05)$. Likewise, the results of item 5 indicate that the item has a significant difference from the neutral value 3 , as the sig value is less than 0.05 . Moreover, the average value that is greater than 3 indicates that the respondents agree with item 5 . The average of the five items related to the advantage factors is equal to $3.51(\mu=3.51>3)$. Consequently, these results indicate that the complexity factor has a significant role in social media adoption. This result is in line with the study by Abubakar et al. (2017) which highlighted the importance of complexity as a factor that affects social media adoption within local NGOs.

Table 4. Complexity

\begin{tabular}{|c|c|c|c|c|c|}
\hline Complexity & Mean & Std. Deviation & $\mathbf{t}$ & df & Sig. (2- \\
\hline $\begin{array}{l}\text { 1. "Interaction with social media is clear and } \\
\text { understandable?" }\end{array}$ & 3.6458 & 1.29760 & 2.101 & 95 & .038 \\
\hline 2. "Social media is flexible to interact with?" & 3.6250 & 1.29980 & 3.374 & 95 & .001 \\
\hline 3. "I find social media easy to use?" & 3.5625 & 1.32833 & 4.149 & 95 & .000 \\
\hline $\begin{array}{l}\text { 4. "It is easy to become skillful at using social } \\
\text { media?" }\end{array}$ & 3.4792 & 1.39155 & 4.877 & 95 & .000 \\
\hline $\begin{array}{l}\text { 5. "I find it easy to get social media to do what I } \\
\text { want to do?" }\end{array}$ & 3.2813 & 1.31151 & 4.711 & 95 & .000 \\
\hline Average & 3.5187 & & & & \\
\hline
\end{tabular}

\subsection{Top Management Support}

As shown in Table 5, item 1 (Top management in our NGO is interested in adopting social media) has the highest average (3.51) and a sig value equal to .000 and less than $.05(\mu=3.4>3 ; p=.000<.05)$. Therefore, item 1 is found to be statistically significant to the mean value, as the sig value is less than 0.05 . In addition, the results show that the respondents agree with this statement, as the average value is greater than 3 . Item 3 (Top management in our NGO has shown support for social media adoption) has the lowest average (3.42) with a sig value of $.001(\mu=3.42>3 ; p=.001<05)$. Likewise, the results of item 3 indicate that the item shows a significant difference from the neutral mean value. Consequently, it shows that the respondents agree with this statement, as the average value is greater than 3. The average of the three items of competitive pressure is equal to 3.47 ( $\mu=$ $3.47>3$ ) and the significant $p$ value indicates that the top management support factor has a significant role in social media adoption.

Saldanha and Krishnan (2012) indicated that studies on top management support in the context of social media adoption are inadequate. Therefore, a need for future researches is essential to confirm the influence of top management support factor on social media adoption. Hence, investigating the factor of top management support in this study might provide great value to social media literature for all businesses in general and for NGOs in particular.

Table 5. Top Management Support

\begin{tabular}{|c|c|c|c|c|c|}
\hline Top Management Support & Mean & Std. Deviation & $\mathbf{t}$ & df & $\begin{array}{l}\text { Sig. }(2- \\
\text { tailed) }\end{array}$ \\
\hline $\begin{array}{l}\text { 1. "Top management in our NGO is interested in } \\
\text { adopting social media" }\end{array}$ & 3.5104 & 1.21391 & 4.120 & 95 & .000 \\
\hline $\begin{array}{l}\text { 2. "Top management in our NGO considers } \\
\text { social media adoption important" }\end{array}$ & 3.4896 & 1.28959 & 3.720 & 95 & .000 \\
\hline $\begin{array}{l}\text { 3. "Top management in our NGO has shown } \\
\text { support for social media adoption" }\end{array}$ & 3.4271 & 1.19424 & 3.504 & 95 & .001 \\
\hline Average & 3.47 & & & & \\
\hline
\end{tabular}




\subsection{Bandwagon Pressure}

As shown in Table 6, the first item (We choose to adopt social media because many other NGOs are already using it) has an average of 3.05 and a sig value equal to $.555(\mu=3.05=3 ; p=.555>.05)$. Therefore, item 1 shows insignificant difference from the neutral value of 3 , which indicates that the respondents neither agree nor disagree with this statement. The second item shows an average of 2.9 with a sig value of $.706(\mu=2.9<3 ; p=.706>.05)$. This also indicates that item 2 shows insignificant difference from the mean value and indicates that respondents are neutral with this statement. However, the average of the two items is equal to $2.9(\mu=2.9<3)$ with a mean value less than 3 . Therefore, it can be concluded that the bandwagon pressure factor does not have a significant role in social media adoption.

Yoon and George (2013) examined the role of bandwagon pressure in social media adoption within profitable organizations. According to them, bandwagon pressure is found to have a great influence on the decision of managers to adopt a new innovation. According to Sinclaire and Vogus (2011) and Rahbi (2017), the main factor that motivates organizations to adopt social media is that their competitors and customers are actively using them.

Table 6. Bandwagon Pressure

\begin{tabular}{lccccc}
\hline \multicolumn{1}{c}{ Bandwagon Pressure } & Mean & $\begin{array}{c}\text { Std. } \\
\text { Deviation }\end{array}$ & t & df & $\begin{array}{c}\text { Sig. (2- } \\
\text { tailed) }\end{array}$ \\
\hline $\begin{array}{l}\text { 1. "We choose to adopt social media because many } \\
\text { other NGOs are already using it?" }\end{array}$ & 3.0521 & 1.34845 & -.592 & 95 & .555 \\
2. "We follow others in adopting social media?" & 2.9271 & 1.20739 & .378 & 95 & .706 \\
Average & $\mathbf{2 . 9 8 9 6}$ & & & & \\
\hline
\end{tabular}

4.6 Competitive Pressure

As shown in Table 7, item 1 (social media would allow our NGO stronger advocacy advantage) has the highest average (3.46) and a sig value less than .05 equal to $.000(\mu=3.4>3 ; p=.000<.05)$. Therefore, item 1 shows that there is a significant difference from the neutral value of 3 with a mean value great than 3 . This indicates that the respondents agree with item 1. Item 3 (social media would increase our NGO ability to outperform other NGOs) has the lowest average of 3.39 with a sig value of $.001(\mu=3.39>3 ; p=.001<.05)$. This indicates that this item also shows significant difference from the neutral value of 3 with an average value greater than 3 . This indicates that the respondents do agree with item 3 . The average of the three items related to competitive pressure is equal to $3.43(\mu=3.4>3)$. Therefore, the results of the sig value and the mean value indicate that the competitive pressure factor has a significant role in social media adoption. Bakar (2018) and Rahbi (2017) confirmed that competitive pressure has a significant impact on social media adoption within public and private organizations.

Table 7. Competitive Pressure

\begin{tabular}{|c|c|c|c|c|c|}
\hline Competitive Pressure & Mean & $\begin{array}{c}\text { Std. } \\
\text { Deviation }\end{array}$ & $\mathbf{t}$ & df & $\begin{array}{l}\text { Sig. }(2- \\
\text { tailed) }\end{array}$ \\
\hline $\begin{array}{l}\text { 1. "Social media would allow our NGO stronger } \\
\text { advocacy advantage?" }\end{array}$ & 3.4688 & 1.25617 & 3.656 & 95 & .000 \\
\hline $\begin{array}{l}\text { 2. "Social media would allow our NGO to } \\
\text { generate more fund?" }\end{array}$ & 3.4375 & 1.22098 & 3.037 & 95 & .003 \\
\hline $\begin{array}{l}\text { 3. "Social media would increase our NGO ability } \\
\text { to outperform other NGOs?" }\end{array}$ & 3.3958 & 1.27716 & 3.511 & 95 & .001 \\
\hline Average & 3.43 & & & & \\
\hline
\end{tabular}

\section{Discussion and Conclusion}

The results indicate a good awareness of the significance of social media for Local NGOs in Yemen. Among the Yemeni local NGOs included in the sample, eleven NGOs are adopters of at least three social media platform, suggesting that social media is gaining the significance and impact of these tools on the performance of Yemeni local NGOs. The results also show that around two-third (73\%) of individuals in the target local NGOs in Yemen have either moderate or an extensive utilization of social media, whereas $78 \%$ have been using social media for more three years and more. The results further show that social media adoption is obvious in the Yemeni local NGOs with wide acceptance and good awareness. 
The study adopts a TOE-based model for social media adoption in Yemeni local NGOs. Descriptive statistics that include maximum, minimum, means, standard deviations, and sig value data are used to examine the importance of the initially-identified 6 TOE factors (Technological Factors: perceived benefit, compatibility, complexity; Organizational Factor: top management support; Environmental Factors: bandwagon pressure and Competitive pressure) on the adoption of social media technologies by Local NGOs in Yemen. The statistical analysis reveals that five factors are found to significantly effect on social media adoption. The three technology factors (perceived benefit, compatibility, complexity) are found to have a significant role in social media adoption. Top management support is also found to affect the decisions of NGOs to adopt social media. Regarding the environmental factors, the study reveals that only one factor (competitive pressure) is identified as playing an important role in motivating local NGOs to adopt social media platforms. However, the study finds that bandwagon pressure is the only factor that shows insignificant role in social media adoption.

Social media adoption difference among the eleven NGOs is also investigated using one-way analysis of variance (ANOVA) to determine whether there are any statistically significant differences among the eleven local NGOs. Five questions related to social media adoption are added to the survey to measure whether local NGOs in Yemen are social media adopters. The results of variance analysis of four questions out of five shows that there are insignificant differences in social media adoption among the eleven local NGOs. These results show that local NGOs in Yemen use similar social media strategies. The results also indicate that there is a unanimous agreement on the importance of social media adoption among local NGOs in Yemen.

\section{Recommendations}

Understanding the significance of social media applications to local NGOs, the following recommendations are derived from the finding of this study. Advocates of social media adoption within local NGOs (e.g., decisionmakers and communications officers) are recommended to use the data of this study to inform managers on the essential factors required when adopting social media. Understanding the factors related to adoption of social media will help decision-makers be in a better position to enhance future social media adoption. In addition, this can help managers and communication officers develop adoption strategies to accomplish the best outcomes of social media utilizations.

Managers of NGOs are also recommended to develop specific procedures and policies for social media adoption, which include a task force dedicated to accomplish the implementation of these procedures. Local NGOs should seek the opportunities of being an early adopter of social media. Being an early adopter can increase their outreach with local and international communities including donors and community stakeholders.

Local NGOs are also recommended to consider experimenting with different social media platforms to help them understand the potential utilization of social media and outreach more local and international audience. NGOs managers are recommended to dedicate time to attend social media related meetings and request regular reports on social media progress and updates to be submitted and presented by the dedicated staff. NGOs are recommended to provide training to their communication staff to get the state-of-the-art information on social media utilization. Communication staff members are also recommended to hold workshops to all members of the NGO, emphasizing the importance of social media contribution and how they can achieve their projects goals using social media platforms.

\section{Research Limitations}

Although this study contributes to the literature, it has several limitations that can be addressed in future research. First, this study focuses on social media adoption in local NGOs in Yemen, but it does not point out social media adoption in international NGOs in Yemen. A comparison study might be needed to examine the differences and similarities between international and local NGOs in Yemen with respect to social media adoption. Another study can focus on the factors that determine the impact of social media adoption on local organizations or small and medium-sized enterprises (SMEs). Conducting this research can open different doors for future researchers to have clear image of the factors that influence social media adoption within different sectors.

Moreover, the context of this study is restricted to Yemeni local NGOs. The structure, operation system, and external environment of local NGOs are different from one country to another. Therefore, it is important to consider the current context of Yemeni civil war. The results of this study may not be applicable to understand the factors that motivate social media adoption in local NGOs in other countries. Replicating this study in different environments might show different results and implications.

Individuals participating in this study are from 11 local NGOs out of 36 local NGOs in Yemen, which are registered in the United Nation System. Therefore, larger samples would provide better quality in the results. 
Finally, while this study focuses on adoption, it ignores other factors that focus on the way NGOs in Yemen are using social media to develop relationship with communities, donors etc.

\section{Future Research}

The following ideas can provide a way to go for any further research. In fact, this study concentrates only on measuring the adoption of social media within local NGOs in Yemen. Therefore, emphasizing other factors that can influence social media adoption such as service and system quality might provide more knowledge on the impact of social media adoption on NGOs. Examining other factors related to TEO model can also add a great value to the literature of social media adoptions.

Furthermore, the data of this study is gathered mainly from local NGOs in Yemen. Therefore, researches can also duplicate the findings of this study but in different context, which will help determining the relevance of the findings. In addition to covering other geographical locations, the study can also be extended to cover other international NGOs including United Nations agencies.

Finally, this study focuses on social media adoption represented by different platforms such as social networking, blogs, micro-blogs, and virtual world application. Therefore, the factors that influence the adoption of each social media application can be different. Future research can conduct an inclusive study on each social media platform separately. This can provide a valuable data on whether the factors that influence social media adoption are similar or different form one social media platform to another.

\section{References}

Abubakar, M., Patricia, M., Samuel, O., \& Totolo, A. (2017). Factors affecting adoption of social media by women's non-governmental organizations. International Journal of Library and Information Science, 9 (9), 96-106.

Aghaunor and Fotoh (2006), A Framework for Electronic Commerce Adoption: A Study In Kaduna State, Nigeria. Science World Journal, 11(4), 233-241.

Al-Qirim, N. (2007). A research trilogy into e-commerce adoption in small businesses in New Zealand. Electronic Markets, 17(4), 263-285.

AlSharji, A., Ahmad, S. Z., \& Abu Bakar, A. R. (2018). Understanding social media adoption in SMEs: Empirical evidence from the United Arab Emirates. Journal of Entrepreneurship in Emerging Economies, 10 (2), 302-328.

Andriole, S. J. (2010). Business impact of Web 2.0 technologies. Communications of the ACM, 53(12), 67-79.

Andzulis, J., Panagopoulos, N. G., \& Rapp, A. (2012). A review of social media and implications for the sales process. Journal of Personal Selling \& Sales Management, 32(3), 305-316.

Aral, S., Dellarocas, C. and Godes, D. (2013) 'Introduction to the Special Issue-Social Media and Business Transformation: A Framework for Research', Information Systems Research, 24(1), pp. 3-13.

Battaglia, L. S. (2016). Social networks. Retrieved from: https://medialandscapes.org/country/yemen

Baxter, G. J., Connolly, T. M., \& Stansfield, M. H. (2010). Organisational blogs: Benefits and challenges of implementation. The Learning Organization, 17(6), 515-528.

Beatty, R. C., Shim, J., \& Jones, M. C. (2001). Factors influencing corporate Web site adoption: A time-based assessment. Information \& Management, 38(6), 337-354.

Bonsón, E., Torres, L., Royo, S., \& Flores, F. (2012). Local e-government 2.0: Social media and corporate transparency in municipalities. Government Information Quarterly, 29(2), 123- 132.

Cao, Y., Ajjan, H., Hong, P., \& Le, T. (2018). Using social media for competitive business outcomes: An empirical study of companies in China. Journal of Advances in Management Research, 15(2), 211-235. https://doi.org/10.1108/JAMR-05-2017-0060

Cesaroni, F. M., \& Consoli, D. (2015). Are small businesses really able to take advantage of social media? Electronic Journal of Knowledge Management, 13(4).

Chang, A. M., \& Kannan, P. (2008). Leveraging Web 2.0 in government. Washington, D.C.: IBM Center for the Business of Government. Retrieved from http://www.businessofgovernment.ort/pdfs/ChangReport2.pdf

Chau, P. Y., \& Tam, K. Y. (1997). Factors affecting the adoption of open systems: An exploratory study. MIS Quarterly, 21(1), 1-24.

Coco, G. A. (2014). Social media evaluation for non-profit organizations. Sweden: Uppsala University.

Dadashzadeh, M. (2010). Social media in government: From e-government to e-governance. Journal of Business \& Economics Research, 8(11), 81-86.

Damanpour, F., \& Schneider, M. (2009). Characteristics of innovation and innovation adoption in public organizations: Assessing the role of managers. Journal of Public Administration Research and Theory, $19(3), 495-522$. 
Ellison, N., \& Hardey, M. (2013). Social media and local government: Citizenship, consumption, and democracy. Local Government Studies, 40(1), 21-40.

Flanagin, J. (2006). Social pressures on organizational Website adoption. Human Communication Research, 26(4), 618-646.

Gangwar, H., Date, H., \& Ramaswamy, R. (2015). Understanding determinants of cloud computing adoption using an integrated TAM-TOE modelnull. Journal of Ent Info Management, 28(1), 107-130.

Grandon, E., \& Pearson, J. (2004). E-Commerce adoption: Perceptions of managers/owners of small and medium sized firms in Chile. Communications of the Association for Information Systems, 42(1), pp. 197-216.

Haller, S. A., \& Siedschlag, I. (2011). Determinants of ICT adoption: Evidence from firm-level data. Applied Economics, 43(26), 3775-3788.

Hameed, M. A., Counsell, S., \& Swift, S. (2012). A conceptual model for the process of IT innovation adoption in organizations. Journal of Engineering and Technology Management, 29(3), 358-390.

Hattez, M. C. (2015). Mass media effects on non-governmental. Lausanne Switzerland: University of Lausanne.

Henderson, et al (2012). Authentic dialogue? The role of "friendship" in a social media recruitment campaign. Journal of Communication Management, 14(3), 237-257.

Hoegg, R., Martignoni, R., Meckel, M., \& Stanoevska-Slabeva, K. (2006). Overview of business models for Web 2.0 communities. Paper presented at the Proceedings of GeNeMe 2006, Dresden, Germany.

Howard, A. E. (2012). Connecting with communities: How local governments is using social media to engage with citizens. Sydney: ANZSOG Institute for Governance at the University of Canberra and Australian Centre of Excellence for Local Government.

Iacovou, C.L., Benbasat, I. and Dexter, A.S. (1995) 'Electronic data interchange and small organizations: adoption and impact of technology', MIS quarterly 13(2), 465-485.

Jeon, Han \& Lee, (2006). Determining factors for the adoption of e-business: The case of SMEs in Korea. Applied Economics 38(16), 1905-1916

Jeyaraj, A., Rottman, J. W., \& Lacity, M. C. (2006). A review of the predictors, linkages, and biases in IT innovation adoption research. Journal of Information Technology, 21(1), 1- 23.

Kane, G. C., Alavi, M., Labianca, G., \& Borgatti, S. P. (2014). What's different about social media networks? A framework and research agenda. MIS quarterly, 38(1), 275-304.

Kaplan, A. M., \& Haenlein, M. (2010). Users of the world, unite! The challenges and opportunities of social media. Business Horizons, 53(1), 59-68.

Kapurubandara, M., \& Lawson, R. (2006). Barriers to adopting ICT and e-commerce with SMEs in developing countries: An exploratory study in Sri Lanka. Proceedings of the 2006 Collector Conference on Electronic Commerce. $\quad$ Retrieved from http://www.collecter2006.unisa.edu.au/Paper\%209\%20Mahesha\%20Kapurubandara.pdf

Kuan, K. K., \& Chau, P. Y. (2001). A perception-based model for EDI adoption in small businesses using a technology-organization-environment framework. Information \& management, 38(8), 507-521.

Lim, S. B., \& Palacios-Marques, D. (2010). Culture and purpose of Web 2.0 service adoption: A study in the USA, Korea and Spain. The Service Industries Journal, 31(1), 123-131.

Mehrtens, J., Cragg, P. B., \& Mills, A. M. (2001). A model of Internet adoption by SMEs.Information \& Management, 39(3), 165-176.

Meijer, A., \& Thaens, M. (2010). Alignment 2.0: Strategic use of new Internet technologies in government. Government Information Quarterly, 27(2), 113-121.

Mergel, I., \& Bretschneider, S. I. (2013). A three-stage adoption process for social media use in government. Public Administration Review, 73(3), 390-400.

Merrill, T., Latham, K., Santalesa, R., \& Navetta, D. (2011). Social media: The business benefits may be enormous, but can the risks reputational, legal, operational-be mitigated. ACE Limited, 6 (2), 13-22.

Moon, M. J., \& Norris, D. F. (2005). Does managerial orientation matter? The adoption of reinventing government and e-government at the municipal level. Information Systems Journal, 15(1), 43-60.

Nah, S., \& Saxton, G. D. (2013). Modeling the adoption and use of social media by nonprofit organizations. New Media \& Society, 15(2), 294-313.

OCHA. (2019). Yemen Humanitarian Fund Annual Report 2018. Sanaa: OCHA Yemen.

Oliveira, T., \& Martins, M. F. (2011). Literature review of information technology adoption models at firm level. The Electronic Journal Information Systems Evaluation, 14(1), 110-121.

O'Reilly, T. (2007). What is Web 2.0: Design patterns and business models for the next generation of software. Communications and Strategies, 65 (17), 347-368

Osimo, D. (2008). Web 2.0 in government: Why and how. Joint Research Centre, European Commission: Institute for Prospective Technological Studies (IPTS). Retrieved from http://ftp.jrc.es/EURdoc/JRC45269.pdf

Parveen, F. (2012). Impact of social media usage on organizations. Paper presented at the Pacific Asia Conference on Information Systems, Ho Chi Minh City, Vietnam. Retrieved from https://citeseerx.ist.psu.edu/viewdoc/download?doi=10.1.1.1072.8737\&rep=rep1\&type=pdf 
Parveen, F., Jaafar, N. I., \& Ainin, S. (2015). Social media usage and organizational performance: Reflections of Malaysian social media managers. Telematics and Informatics, 32(1), 67-78.

Petter, S., DeLone, W., \& McLean, E. R. (2013). Information systems success: The quest for the independent variables. Journal of Management Information Systems, 29(4), 7-62.

Premkumar, G. (2003). A meta-analysis of research on information technology implementation in small business. Journal of Organizational Computing and Electronic Commerce, 13(2), 91-121.

Rahbi, H. S. (2017). Factors influencing social media adoption in small and medium enterprises (SMEs). London: Brunel University London.

Ramdani, B., Kawalek, P., \& Lorenzo, O. (2009). Predicting SMEs' adoption of enterprise systems. Journal of Enterprise Information Management, 22(1/2), 10-24.

Rogers, E. M. (1995). Diffusion of innovations. New York: The Free Press.

Rosenkopf, L., \& Abrahamson, E. (1999). Modeling reputational and informational influences in threshold models of bandwagon innovation diffusion. Computational \& Mathematical Organization Theory, 5(4), 361-384.

Safko, J., \& Brake, D. K. (2009). The social media Bible. Hoboken, NJ: Wiley.

Saldanha, T. J. V., \& Krishnan, M. S. (2012). Organizational adoption of Web 2.0 technologies: An empirical analysis. Journal of Organizational Computing and Electronic Commerce, 22(4), 301-333.

Sinclaire, J., \& Vogus, C. (2011). Adoption of social networking sites: An exploratory adaptive structuration perspective for global organizations. Information Technology and Management, 12(4), 293-314.

Sivarajah, U., Irani, Z., \& Jones, S. (2014). Application of Web 2.0 technologies in egovernment: A United Kingdom case study. Paper presented at the 47th Hawaii International Conference on System Sciences (HICSS), Waikoloa, HI.

Sun, H., \& Douglas, M. (2013). Using social media to promote international collaboration, Pennsylvania Libraries: Research \& Practice, 1(1), 60-74.

Tan and Teo (1998), A Contingency Model of Internet Adoption in Singapore, International Journal of Electronic Commerce 2(2), 95-118

Teo, T. S. H., Lin, S., \& Lai, K. H. (2009). Adopters and non-adopters of e-procurement in Singapore: An empirical study. The International Journal of Management Science, 37(5), 972-987.

Thackery, R., Neiger, B. L., Smith, A. K., \& Van Wagenen, S. B. (2012). Adoption and use of social media among public health departments. BMC Public Health, 12(3), 242-271.

Thong, J. Y. L. (1999). An integrated model of information systems adoption in small businesses. Journal of Management Information Systems, 15(4), 187-214.

Venkatesh, V., \& Bala, H. (2013). Adoption and impacts of interorganizational business process standards: Role of partnering synergy. Information Systems Research, 23(4), 1131-1157.

Verheyden, M., \& Goeman, K. (2013). Does (company) size matter? Differences in social media usage for business purposes. Journal of Applied Quantitative Methods, 8(4), 3-16.

Vistbacka, S. (2017). Crisis management in social media - Maintaining the organizational image. Jyväskylä University School.

Ward, C. (2011). Social media and crisis communication. Muncie, Indiana: Ball State University.

Waters, R. D., \& Williams, J. M. (2011). Squawking, tweeting, cooing, and hooting: Analyzing the communication patterns of government agencies. Journal of Public Affairs, 11(4), 353-363.

Whitaker, L. (2014). Nonprofit organizations \& social media fundraising. University of Kentucky.

Yates, D., Wagner, C., \& Majchrzak, A. (2010). Factors affecting shapers of organizational wikis. Journal of the American Society for Information Science and Technology, 61(3), 543-554.

Yoon, T. E., \& George, J. F. (2013). Why aren't organizations adopting virtual worlds? Computers in Human Behavior, 29(3), 772-790.

\section{Copyrights}

Copyright for this article is retained by the author(s), with first publication rights granted to the journal. This is an open-access article distributed under the terms and conditions of the Creative Commons Attribution license (https://creativecommons.org/licenses/by-sa/4.0/). 